\title{
The management of tetanus in adults in an intensive care
}

\section{unit in Southern Vietnam [version 1; peer review: 1 approved,}

\section{2 approved with reservations]}

\section{Nguyen Van Hao ${ }^{1,2 *}$, Lam Minh Yen ${ }^{3 *}$, Rachel Davies-Foote (iD $4^{*}$, Truong Ngoc Trung ${ }^{1}$, Nguyen Van Thanh Duoc ${ }^{1}$, Vo Thi Nhu Trang ${ }^{5}$, Phung Tran Huy Nhat (iD), Du Hong Duc (iD)3, Nguyen Thi Kim Anh1, Pham Thi Lieu3, Tran Thi Diem Thuy (D), Duong Bich Thuy1, Nguyen Thanh Phong1, Nguyen Thanh Truong ${ }^{1}$, Pham Ba Thanh'1, Dong Thi Hoai Tam ${ }^{1,2}$, Zudin Puthucheary6,7, C Louise Thwaites (iD) 3,8}

\footnotetext{
${ }^{1}$ Hospital for Tropical Diseases, Ho Chi Minh City, Vietnam

2University of Medicine and Pharmacy, Ho Chi Minh City, Vietnam

${ }^{3}$ Oxford University Clinical Research Unit, Ho Chi Minh City, Vietnam

${ }^{4}$ London School of Hygiene \& Tropical Medicine, London, UK

${ }^{5}$ Gia Dinh Hospital, Danang City, Vietnam

${ }^{6}$ William Harvey Research Institute, Queen Mary, University of London, London, UK

${ }^{7}$ Royal London Hospital, London, UK

${ }^{8}$ Centre for Tropical Medicine and Global Health, University of Oxford, Oxford, UK

* Equal contributors
}

V1 First published: 12 May 2021, 6:107
https://doi.org/10.12688/wellcomeopenres.16731.1

Latest published: 31 Aug 2021, 6:107

https://doi.org/10.12688/wellcomeopenres.16731.2

\section{Abstract}

Background: Tetanus remains common in many low- and middleincome countries (LMICs) yet the evidence base guiding management of this disease is extremely limited, particularly with respect to contemporary management options. Sharing knowledge about practice may facilitate improvement in outcomes elsewhere.

Methods: We describe clinical interventions and outcomes of 180 adult patients $\geq 16$ years-old with tetanus enrolled in prospective observational studies at a specialist infectious diseases hospital in Southern Vietnam. Patients were treated according to a holistic management protocol encompassing wound-care, antitoxin, antibiotics, symptom control, airway management, nutrition and deescalation criteria.

Results: Mortality rate in our cohort was 2.8\%, with 90 (50\%) patients requiring mechanical ventilation for a median 16 [IQR 12-24] days. Median [IQR] duration of ICU stay was 15 [8-23] days. Autonomic nervous system dysfunction occurred in 45 (25\%) patients. Hospital

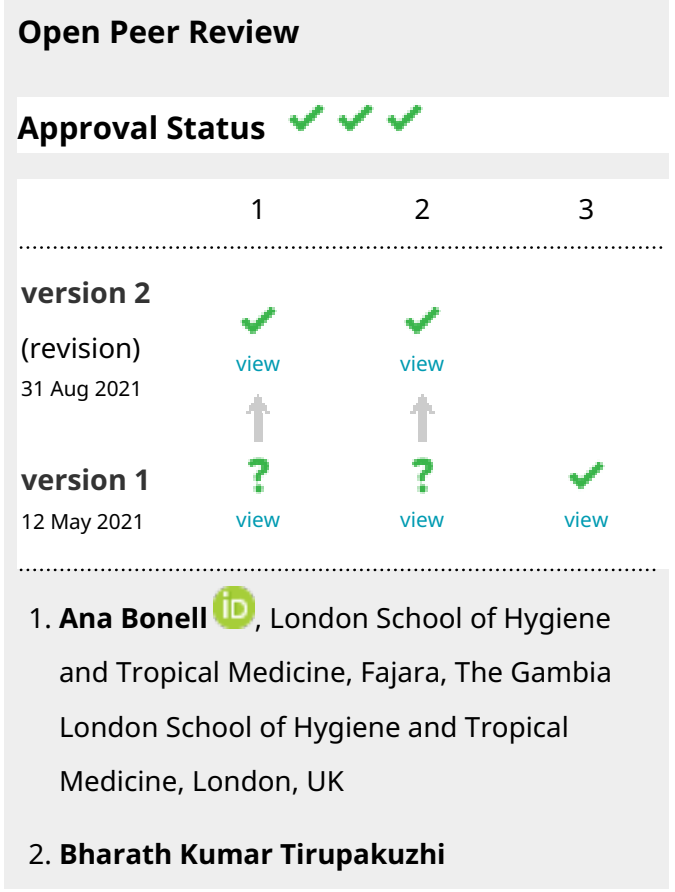

Page 1 of 16 
acquired infections occurred in 77 (43\%) of patients.

Conclusion: We report favourable outcomes for patients with tetanus in a single centre LMIC ICU, treated according to a holistic protocol. Nevertheless, many patients required prolonged intensive care support and hospital acquired infections were common.

\section{Keywords}

Tetanus, management, treatment, low middle income country, LMIC, intensive care unit, ICU

Vijayaraghavan
Chennai, India
3. Madiha Hashmi
Karachi, Pakistan
Any reports and responses or comments on the
article can be found at the end of the article.

\section{Corresponding author: C Louise Thwaites (Ithwaites@oucru.org)}

Author roles: Hao NV: Conceptualization, Investigation, Methodology, Project Administration, Resources, Supervision, Writing - Review \& Editing; Yen LM: Conceptualization, Data Curation, Investigation, Methodology, Project Administration, Supervision, Writing - Review \& Editing; Davies-Foote R: Conceptualization, Data Curation, Formal Analysis, Methodology, Writing - Original Draft Preparation, Writing - Review \& Editing; Trung TN: Data Curation, Investigation, Methodology, Writing - Review \& Editing; Duoc NVT: Data Curation, Investigation, Methodology, Writing - Review \& Editing; Trang VTN: Data Curation, Investigation, Project Administration, Writing Review \& Editing; Nhat PTH: Data Curation, Investigation, Project Administration, Writing - Review \& Editing; Duc DH: Formal Analysis, Writing - Original Draft Preparation, Writing - Review \& Editing; Anh NTK: Data Curation, Project Administration, Writing - Review \& Editing; Lieu PT: Data Curation, Project Administration, Writing - Review \& Editing; Thuy TTD: Project Administration, Resources, Writing - Review \& Editing; Thuy DB: Data Curation, Project Administration, Writing - Review \& Editing; Phong NT: Resources, Supervision, Writing - Review \& Editing; Truong NT: Project Administration, Resources, Supervision, Writing - Review \& Editing; Thanh PB: Project Administration, Resources, Writing - Review \& Editing; Tam DTH: Methodology, Supervision, Writing - Review \& Editing; Puthucheary Z: Investigation, Methodology, Supervision, Writing - Original Draft Preparation, Writing - Review \& Editing; Thwaites CL:

Conceptualization, Funding Acquisition, Methodology, Project Administration, Resources, Supervision, Writing - Original Draft Preparation, Writing - Review \& Editing

Competing interests: No competing interests were disclosed.

Grant information: The work was supported by the Wellcome Trust [107367; 089276].

The funders had no role in study design, data collection and analysis, decision to publish, or preparation of the manuscript.

Copyright: $(2021$ Hao NV et al. This is an open access article distributed under the terms of the Creative Commons Attribution License, which permits unrestricted use, distribution, and reproduction in any medium, provided the original work is properly cited.

How to cite this article: Hao NV, Yen LM, Davies-Foote R et al. The management of tetanus in adults in an intensive care unit in Southern Vietnam [version 1; peer review: 1 approved, 2 approved with reservations] Wellcome Open Research 2021, 6:107 https://doi.org/10.12688/wellcomeopenres.16731.1

First published: 12 May 2021, 6:107 https://doi.org/10.12688/wellcomeopenres.16731.1 


\section{Introduction}

Tetanus is a vaccine-preventable disease that remains a common cause of acute critical illness in low-income and middle-income countries (LMICs) ${ }^{1}$. Signs and symptoms are due to the effects of tetanus toxin in the central nervous system and management is based on three key strategies: blocking further tetanus toxin release $^{2}$, neutralising unbound toxin ${ }^{3}$, and alleviating effects of already-bound toxin; namely muscle spasms and autonomic nervous system dysfunction ${ }^{1,4,5}$. With access to critical care interventions such as mechanical ventilation and advanced physiological monitoring, muscle spasms and autonomic nervous system dysfunction (ANSD) can be more easily managed ${ }^{6-8}$. These interventions are now available in many LMIC intensive care units (ICUs); however, their availability is often not associated with improved outcomes ${ }^{9,10}$.

As almost all tetanus occurs in settings with limited capacity for clinical trials, the evidence base for tetanus management remains limited. There are few randomized clinical trials to support common management strategies and, in the absence of high-quality evidence, observational studies and case series become the key elements in guiding treatment. The Hospital for Tropical Diseases, Ho Chi Minh City, has been a tertiary referral centre for tetanus for over 30 years and has developed and implemented a specific holistic management protocol for patients with tetanus. The ICU continues to admit several hundred adult patients with tetanus every year and reports outcomes comparable with those from high income settings $s^{7,11}$.

The overall aim of this paper is to pragmatically describe the intensive care management of adult tetanus in a LMIC setting but nevertheless one with amongst the lowest reported case fatality rate worldwide ${ }^{12}$

\section{Methods}

\section{Setting}

The Hospital for Tropical Diseases (HTD), Ho Chi Minh City is a tertiary referral centre for infectious diseases serving Southern Vietnam. Previously the hospital housed a special tetanus ICU but whilst this no longer exists, the hospital's adult ICU continues to receive 250-350 adult patients with tetanus annually. The principles of tetanus management described above have been incorporated into a specific treatment protocol (Figure 1), which has been applied consistently to all patients over a 10 year period $^{12}$. In addition to pharmacological interventions, the protocol includes directions for airway management, nutrition and nursing observations. It also includes criteria for de-escalation and discharge from hospital.

\section{Participants and data collection}

Data on management and outcome of patients treated with this protocol were collected from prospective observational studies of two cohorts of patients $\geq 16$ years old admitted to the hospital's ICU with a diagnosis of generalized tetanus; the first from August 2016 - March 2017 and the second from January - July 2018. For patients enrolled between August 2016 and March 2017, additional exclusion criteria were: (i) not speaking Vietnamese, (ii) not being able to walk before admission.
Baseline and clinical variables including patient demographic details, tetanus severity indicators and management interventions and complications were collected prospectively on all enrolled subjects. Enrolled patients were followed daily until hospital discharge. Previously described definitions were applied for hospital acquired infections ${ }^{13}$. Autonomic nervous system dysfunction (ANSD) was defined as at least three of: heart rate $>100$ beats per minute (bpm), systolic blood pressure $>140 \mathrm{mmHg}$, mean arterial pressure $<60 \mathrm{mmHg}$, pyrexia $>38^{\circ} \mathrm{C}$, and fluctuating blood pressure. All features should be present within one day with no other apparent cause ${ }^{14}$. Sensitivity evaluation of mortality rates within this study was performed by comparing with overall hospital database for outcomes of all patients with tetanus (ICD10 code A35) during the period 2016- 2018.

\section{Statistical analysis}

Descriptive statistics were used to describe the sample with the median and interquartile range (IQR) for continuous data, and count and percentage for categorical data. Due to small numbers of those who died, no comparative statistics have been performed. All analyses were carried out in Stata (StataCorp) version 16. Missing data are included and described in tables.

\section{Ethics statement}

This study was approved by the London School of Hygiene and Tropical Medicine (LSHTM) ethics committee, the Oxford Tropical Medicine Ethics Committee (OxTREC) and the local HTD ethics committee (Refs 16904, 596-16, 816 QD-BVBND, 38-17, 494/ QD - SYT respectively.) All participants gave written informed consent to participate before enrolment.

\section{Results}

In total, 180 patients with generalised tetanus admitted to the ICU at HTD between August 2016 and July 2018 were included in this study. Out of a total 160 adult patients with tetanus admitted to the ICU, 80 patients were enrolled during the first period. For the second period, 100 patients were included out of a total of 120 admissions. Reasons for lower enrolment of the first cohort were largely pragmatic due to lack of availability of study staff and more stringent enrolment criteria. The median [IQR] age of the patients was 51.0 [40.8-61.5]. The youngest age was 17 and the oldest 98 years old. Of 180 patients, 73 (40.6\%) had at least one comorbidity and 143/180 (79.4\%) were male. Median Tetanus Severity Score on admission was $1.5[\text { IQR }-3-5]^{15}$. Severe tetanus, defined as Ablett grade 3 or 4 on hospital admission (i.e. spasms interfering with respiration with/without autonomic nervous system dysfunction), was diagnosed in 28 patients (16\%), but an additional $66(37 \%)$ progressed to severe disease during hospitalization.

A summary of the management and complications of the patients during ICU admission are described in Table 1 and Table 2.

\section{Description of the cases who died}

Of the $5 / 180(2.8 \%)$ patients that died, the median age was 79 years [IQR 84-81], compared with 50 years [IQR 40-61] for the $175 / 180(97.2 \%)$ patients who survived; $5 / 5(100 \%)$ were 


\begin{tabular}{|c|c|}
\hline Equine antitoxin: & $\begin{array}{l}400-500 \text { units/kg once by intramuscular injection, maximum } 21,000 \text { units; } \\
\text { Neonates: } 1,000 \text { units/kg once by intramuscular injection }\end{array}$ \\
\hline Human antitoxin & $\begin{array}{l}3000-6000 \text { units as a single dose by slow intramuscular injection, or } 150 \\
\text { units } / \mathrm{kg} \text { by intramuscular injection in multiple sites. }\end{array}$ \\
\hline \multicolumn{2}{|l|}{ 2. Wound Care } \\
\hline Debride \& Clean & $\begin{array}{l}\text { Debride and clean then provide wound care } 1-2 \text { times daily with hydrogen } \\
\text { peroxide. For open fractures make a window in the plaster to allow wound } \\
\text { care. For patients with spasms, give diazepam/ midazolam intravenously } \\
\text { before. }\end{array}$ \\
\hline \multicolumn{2}{|l|}{ 3. Antibiotics } \\
\hline $\begin{array}{l}\text { Metronidazole (7-10 } \\
\text { days) }\end{array}$ & Children: $30-40 \mathrm{mg} / \mathrm{kg} / \mathrm{day}$ in 3 divided doses; Adults: $0.5 \mathrm{~g} 3$ times daily orally \\
\hline $\begin{array}{l}\text { Erythromycin (7-10 } \\
\text { days) }\end{array}$ & Children: $30-50 \mathrm{mg} / \mathrm{kg} / \mathrm{d}$, divided 3 times a day; Adults: $0.5 \mathrm{~g} 3$ times daily, orally \\
\hline Penicillin V ( $7-10$ days) & Adults/children: 100,000 units/kg/day, in 4 divided doses orally \\
\hline Penicillin G (7-10 days) & Adults/children: 150,000 unis $/ \mathrm{kg} /$ day, in 4 divided doses intravenously \\
\hline \multicolumn{2}{|l|}{ 4. Spasm treatment } \\
\hline Diazepam & $\begin{array}{l}\text { Intravenous injection } 0.1-0.3 \mathrm{mg} / \mathrm{kg} \text { every } 2-4 \text { hours, maximum } 10 \mathrm{mg} \text { one dose } \\
\text { and total dose } 1-2 \mathrm{mg} / \mathrm{kg} / \text { day } \\
\text { Orally } 1-3 \mathrm{mg} / \mathrm{kg} / \text { day if well tolerated, maximum of } 20 \mathrm{mg} \text { in one dose } \\
\text { Reduce to half dose in elderly, those with respiratory failure, liver failure, } \\
\text { hypovolemic shock, limited spasms or reduced consciousness. }\end{array}$ \\
\hline Midazolam & $\begin{array}{l}\text { Intravenous injection } 0.05-0.2 \mathrm{mg} / \mathrm{kg} \text { every } 2-3 \text { hours, maximum } 7-10 \mathrm{mg} / \mathrm{dose} \\
\text { in adults, or } 0.05-0.1 \mathrm{mg} / \mathrm{kg} / \mathrm{hour} \text { intravenous infusion, maximum } 7-10 \\
\mathrm{mg} / \text { hour adults } \\
\text { Dose should be titrated to spasms, respiratory failure and conscious level }\end{array}$ \\
\hline \multicolumn{2}{|c|}{ 5. Neuromuscular blocking agents } \\
\hline Pipecuronium & $\begin{array}{l}0.05 \mathrm{mg} / \mathrm{kg} / \mathrm{dose} \text { intravenously, after that } 0.02-0.05 \mathrm{mg} / \mathrm{kg} / \mathrm{hr} \text { to a maximum 2- } \\
3 \mathrm{mg} / \mathrm{hour} \text { continuous intravenous infusion, titrated to spasms }\end{array}$ \\
\hline \multicolumn{2}{|l|}{ 6. Other } \\
\hline Tracheostomy & $\begin{array}{l}\text { Laryngeal spasm } \\
\text { Spasms interfering with respiration } \\
\text { To facilitate endotracheal suction if sputum retention } \\
\text { For neonates and young children use endotracheal intubation }\end{array}$ \\
\hline $\begin{array}{l}\text { Autonomic nervous } \\
\text { system dysfunction }\end{array}$ & Morphine, $\mathrm{MgSO}_{4}$, antihypertension medication, antipyretics, hemofiltration \\
\hline Nutrition & $\begin{array}{l}\text { Enteral nutrition as soon as possible - though nasogastric tube if cannot } \\
\text { swallow } \\
\text { For neonates, mother's milk preferred }\end{array}$ \\
\hline Care and Observation & $\begin{array}{l}\text { Care and careful observation for every patient with spasms with vital sign } \\
\text { monitoring, as well as monitoring spasms, consciousness, wound, fluid } \\
\text { balance/24hs }\end{array}$ \\
\hline $\begin{array}{l}\text { Criteria for removing } \\
\text { tracheostomy }\end{array}$ & $\begin{array}{l}\text { Conscious } \\
\text { No spasms or laryngeal spasm } \\
\text { Little sputum, strong cough }\end{array}$ \\
\hline $\begin{array}{l}\text { Criteria for hospital } \\
\text { discharge }\end{array}$ & $\begin{array}{l}\text { No spasm, (including laryngeal or pharyngeal) } \\
\text { Eating and drinking normally } \\
\text { Able to perform self-care } \\
\text { No need for benzodiazepines or muscle rigidity }\end{array}$ \\
\hline
\end{tabular}

Figure 1. Summary of Tetanus Treatment Protocol Hospital for Tropical Diseases, Ho Chi Minh City.

male and 4/5 (80\%) had comorbidities. On admission, amongst those who died, all $5 / 5(100 \%)$ had difficulty breathing (noted by admitting doctors) compared to $32 / 175$ (18.3\%) for those who survived. The median $\mathrm{SpO}_{2}$ was 94\% [IQR 94-97] compared with 97\% [IQR 95-98] for those who survived and the median white blood cell (WBC) count was 16.8 [14.9-23.9] $\times 10^{9} / \mathrm{L}$ compared with $9.8[7.4-11.8] \times 10^{9} / \mathrm{L}$ for those who survived. Throughout ICU admission, amongst those who died, all 5/5 (100\%) required mechanical ventilation. Two out of five $(40 \%)$ patients that died developed ANSD, compared with $43 / 175(24.6 \%)$ in those who survived.

Three deaths were caused by cardiogenic shock (occurring at days 2, 12 and 15 of ICU admission), one death was due to septic shock secondary to ventilator associated pneumonia (occurring at day 5 of ICU admission) and one was due to ischaemic bowel and perforation (occurring at day 28 of ICU admission). Review of hospital records showed that in total, during the three years 


\begin{tabular}{|c|c|}
\hline Parameter & $\begin{array}{l}\text { Median }[\mathrm{IQR}] \text { or } \\
\text { Count }(\%)\end{array}$ \\
\hline \multicolumn{2}{|l|}{ Interventions } \\
\hline Tracheostomy required & $94(52.2 \%)$ \\
\hline Duration tracheostomy (days) $(n=94)$ & $18.5[15-27]$ \\
\hline Mechanical ventilation required & $90(50 \%)$ \\
\hline Duration mechanical ventilation (days) $(n=90)$ & $16.0[12-24]$ \\
\hline \multicolumn{2}{|l|}{ Pharmaceutical agents required } \\
\hline Duration diazepam required (days) $(n=174)$ & $14[11-20]$ \\
\hline Total dose diazepam $(\mathrm{mg})(\mathrm{n}=174)$ & 585 [295-1352.5] \\
\hline Maximum dose in 24 hours diazepam IV (mg) $(n=97)$ & $80[20-120]$ \\
\hline Maximum dose in 24 hours diazepam oral $(\mathrm{mg})(\mathrm{n}=170)$ & $60[45-120]$ \\
\hline Maximum dose in 24 hours diazepam any route $(\mathrm{mg})(\mathrm{n}=173)$ & $120[60-120]$ \\
\hline Duration midazolam required (days) $(n=109)$ & $10[3-16]$ \\
\hline Total dose midazolam during hospitalization $(\mathrm{mg})(\mathrm{n}=109)$ & 996 [240-1905] \\
\hline Maximum dose in 24 hours midazolam $(\mathrm{mg})(\mathrm{n}=109)$ & $120[92-168]$ \\
\hline Total dose benzodiazepine during hospitalization (mg) & $1627.5[862.5-2526.2]$ \\
\hline Maximum dose in 24 hours benzodiazepine (mg) & $120[120-160]$ \\
\hline Duration magnesium sulphate (days) $(n=50)$ & $5[3-8]$ \\
\hline $\begin{array}{l}\text { Total dose magnesium sulphate during hospitalization }(\mathrm{g}) \\
(\mathrm{n}=50)\end{array}$ & $203[81-336]$ \\
\hline Duration pipecuronium (days) $(n=78)$ & $13[9-17]$ \\
\hline
\end{tabular}

Total dose pipecuronium during hospitalization (mg) (n=78) 410.3 [226.3-558.3]

2016- 2018, 917 adults were admitted with tetanus with an overall case fatality rate of $4 \%$ (including palliative discharges).

\section{Discussion}

We describe clinical features and outcomes of a large cohort of patients with tetanus managed at a specialist tetanus centre. Patients were managed in accordance with a standardized protocol by a team of doctors and nurses with significant experience in tetanus management ${ }^{7}$.

The case fatality rate in this study is $2.8 \%$. This is, to our knowledge, the lowest reported mortality rate for a large series of tetanus patients worldwide ${ }^{12}$, and contrasts with rates reported from many other $\mathrm{LMICs}^{10,16}$. Whilst it is possible that selection bias has influenced our results, our figures are similar to official hospital records over the study period as well as an observational study enrolling patients with severe tetanus from our centre and one other major centre in Vietnam between 2013 and 2015 ${ }^{17}$.
Comparison with contemporary data from other countries is more difficult due to limited reporting of established tetanus severity scores or known prognostic features. Nevertheless, the age of patients in our study (one of the strongest predictors of outcome) is similar to, or even older than, those reported in other centres with worse outcomes ${ }^{10,18,19}$. Similarly, our ventilation rate was $50 \%$ but rates between $50 \%$ and $75 \%$ elsewhere have been associated with mortality rates of $30-35 \%{ }^{10,19,20}$.

We believe that the favourable outcomes at our centre result from two major factors: a clear evidence-based management protocol and care by a highly specialized team with enormous experience in tetanus. Throughout the world, protocolized medical care is encouraged as a means of improving patient outcomes. Ideally, protocols are based on best evidence and can be regularly updated. However, this is not the case for many of the elements of our protocol due to the lack of high-quality contemporary evidence for tetanus management. Nevertheless, 
Table 2. Complications and outcomes of enrolled patients.

\begin{tabular}{|c|c|}
\hline Parameter & $\begin{array}{l}\text { Median [IQR] or } \\
\text { Count }(\%)\end{array}$ \\
\hline \multicolumn{2}{|l|}{ Severity score } \\
\hline $\begin{array}{l}\text { Worst Ablett score during admission*: } \\
1 \\
2 \\
3 \\
4\end{array}$ & $\begin{array}{l}20(11.1 \%) \\
66(36.7 \%) \\
49(27.2 \%) \\
45(25 \%)\end{array}$ \\
\hline \multicolumn{2}{|l|}{ Complications } \\
\hline Autonomic nervous system dysfunction & $45(25 \%)$ \\
\hline Ventilator associated pneumonia & $57(31.7 \%)$ \\
\hline Bacteraemia & $19(10.6 \%)$ \\
\hline Urinary tract infection & $39(21.7 \%)$ \\
\hline Any hospital acquired infection & $77(42.8 \%)$ \\
\hline Pressure ulcer & $18(10 \%)$ \\
\hline \multicolumn{2}{|l|}{ Duration of admission } \\
\hline Length of intensive care unit stay (days) & $15.0[8.0-23.0]$ \\
\hline Length of hospital stay (days) & $25[19.0-34.0]$ \\
\hline \multicolumn{2}{|l|}{ Outcome } \\
\hline Died in hospital** & $5(2.8 \%)$ \\
\hline \multicolumn{2}{|c|}{$\begin{array}{l}\text { * Ablett score: Grade } 1 \text { is mild tetanus with no spasms, Grade } 2 \text { mild } \\
\text { spasms not compromising breathing, Grade } 3 \text { is severe tetanus with } \\
\text { spasms compromising breathing. Ablett Grade } 4 \text { is as Grade } 3 \text { but with } \\
\text { additional signs of autonomic nervous system dysfunction }{ }^{21} \text {. }\end{array}$} \\
\hline
\end{tabular}

the outcomes in our patients to some extent supports their continued use. A limitation of our work is that protocol adherence itself was not specifically measured. Personal experience and treatment intervention data reported herein indicate that adherence was high; however, we have not specifically examined compliance with individual components of the protocol.

Our hospital is a tertiary infectious disease centre and receives patients with tetanus from Southern Vietnam. A highly developed referral system and limited staff turnover within the ICU means that experience in management of tetanus can be more readily easily developed and preserved. Tetanus is a disease where progression continues to occur after hospitalization. Experienced staff may therefore be better able to anticipate complications, and so arrange care and interventions more appropriately. They may also be able to pass on subtle elements of care not outlined in our protocol - for example exactly when to intervene with spasms or how to balance risk of pressure area necrosis and spasm provocation when turning a patient. Finally, as a tertiary infectious disease centre there may be further factors that particularly benefited outcomes, such as more careful prevention or management of hospital acquired infections which are particularly frequent in severe tetanus.

Sharing these forms of tacit knowledge is a challenge for health systems across the world but is most likely to benefit lower resourced settings with less access to specialised training and referral. The current expansion of digital technologies may offer possible solutions. For example, newer technologies in the form of telemedicine or even AI-enabled risk stratification may facilitate dissemination of less explicit knowledge or even simplify analysis of these complex processes.

\section{Conclusions}

We report management and outcome features in a large contemporary cohort of patients with tetanus treated according to a standardized protocol. Survival rates of these patients are high compared to other reported case series. Nevertheless, other outcomes such as duration of hospitalization and mechanical ventilation requirements indicate that tetanus remains a significant burden on healthcare services. Therapies that can reduce these continue to be needed.

\section{Declarations}

Data availability

Oxford University Research Archive. Dataset: Long-term outcome in tetanus cohort: 04TS: https://ora.ox.ac.uk/objects/uuid: af44c622-a7b8-44b2-827e-056623dd49a8 ${ }^{22}$.

This project contains the following underlying data:

- ORA_04TSSF36.xlsx (This is a data set from a clinical observation study. The data was manually entered from case record forms to a specific database. This dataset is from the exported data.)

Data are available under the terms of the Creative Commons Attribution 4.0 International license (CC-BY 4.0).

\section{Acknowledgements}

We would like to thank staff in the adult ICU and Ward D at the Hospital for Tropical Diseases. 
1. Yen LM, Thwaites CL: Tetanus. Lancet. 2019; 393(10181): 1657-68. PubMed Abstract | Publisher Full Text

2. Kumar AVG, Kothari VM, Krishnan A, et al.: Benzathine penicillin, metronidazole and benzyl penicillin in the treatment of tetanus: a randomized, controlled trial. Ann Trop Med Parasitol. 2004; 98(1): 59-63. PubMed Abstract | Publisher Full Text

3. Rodrigo C, Fernando D, Rajapakse S: Pharmacological management of tetanus: an evidence-based review. Crit Care. 2014; 18(2): 217. PubMed Abstract | Publisher Full Text | Free Full Text

4. Filho GTH, Lacerda HR, Albuquerque A, et al.: Sympathetic overactivity and arrhythmias in tetanus: electrocardiographic analysis. Rev Inst Med Trop Sao Paulo. 2007; 49(1): 17-22.

PubMed Abstract | Publisher Full Text

5. Thwaites CL, Yen LM, Loan HT, et al.: Magnesium sulphate for treatment of severe tetanus: a randomised controlled trial. Lancet. 2006; 368(9545): 1436-43.

PubMed Abstract | Publisher Full Text

6. Trieu HT, Lubis IN, Qui PT, et al.: Neonatal tetanus in Vietnam: comprehensive intensive care support improves mortality.J Pediatric Infect Dis Soc. 2016; 5(2): 227-30.

PubMed Abstract | Publisher Full Text | Free Full Text

7. Thwaites $\mathrm{CL}$, Yen $\mathrm{LM}$, Nga NTN, et al.: Impact of improved vaccination programme and intensive care facilities on incidence and outcome of tetanus in southern Vietnam, 1993-2002. Trans R Soc Trop Med Hyg. 2004 98(11): 671-7.

PubMed Abstract | Publisher Full Text

8. Brauner JS, Vieira SRR, Bleck TP: Changes in severe accidental tetanus mortality in the ICU during two decades in Brazil. Intensive Care Med. 2002; 28(7): 930-5.

PubMed Abstract | Publisher Full Text

9. Kyu HH, Mumford JE, Stanaway JD, et al.: Mortality from tetanus between 1990 and 2015: findings from the global burden of disease study 2015. BMC Public Health. 2017: 17(1): 179

PubMed Abstract | Publisher Full Text | Free Full Text

10. da Nóbrega MVD, Reis RC, Aguiar ICV, et al.: Patients with severe accidental tetanus admitted to an intensive care unit in Northeastern Brazil: clinicalepidemiological profile and risk factors for mortality. Braz J Infect Dis. 2016; 20(5): 457-61.

PubMed Abstract | Publisher Full Text

11. Thuy DB, Campbell JI, Thanh TT, et al.: Tetanus in Southern Vietnam: Current
Situation. Am J Trop Med Hyg. 2017: 96(1): 93-96. PubMed Abstract | Publisher Full Text | Free Full Text

12. An VT, Khue PM, Yen LM, et al.: [Tetanus in Ho Chi Minh City, Vietnam: epidemiological, clinical and outcome features of 389 cases at the Hospital for Tropical Diseases]. Bull Soc Pathol Exot. 2015; 108(5): 342-8. PubMed Abstract | Publisher Full Text

13. Loan HT, Yen LM, Kestelyn E, et al.: Intrathecal Immunoglobulin for treatment of adult patients with tetanus: A randomized controlled $2 \times 2$ factorial trial [version 2; peer review: 2 approved]. Wellcome Open Res. 2018; 3: 58. PubMed Abstract | Publisher Full Text | Free Full Text

14. Duong HTH, Tadesse GA, Nhat PTH, et al:: Heart Rate Variability as an Indicator of Autonomic Nervous System Disturbance in Tetanus. Am J Trop Med Hyg. 2020; 102(2): 403-407.

PubMed Abstract | Publisher Full Text | Free Full Text

15. Thwaites $\mathrm{CL}$, Yen $\mathrm{LM}$, Glover $\mathrm{C}$, et al.: Predicting the clinical outcome of tetanus: the tetanus severity score. Trop Med Int Health. 2006; 11(3): 279-87. PubMed Abstract | Publisher Full Text

16. Woldeamanuel YW, Andemeskel AT, Kyei K, et al.: Case fatality of adult tetanus in Africa: Systematic review and meta-analysis. J Neurol Sci. 2016; 368: 292-9.

PubMed Abstract | Publisher Full Text

17. Phu VD, Nadjm B, Duy NHA, et al.: Ventilator-associated respiratory infection in a resource-restricted setting: Impact and etiology. J Intensive Care. 2017; 5(1): 69.

PubMed Abstract | Publisher Full Text | Free Full Text

18. Adekanle $O$, Ayodeji $O$, Olatunde L: Tetanus in a rural setting of South-Western Nigeria: a ten-year retrospective study. Libyan J Med. 2009; 4(2): 78-80. PubMed Abstract | Publisher Full Text | Free Full Text

19. Aziz R, Colombe S, Mwakisambwe G, et al.: Pre-post effects of a tetanus care protocol implementation in a sub-Saharan African intensive care unit. PLoS Negl Trop Dis. 2018; 12(8): e0006667. PubMed Abstract | Publisher Full Text | Free Full Text

20. Tosun S, Batirel A, Oluk AI, et al.: Tetanus in adults: results of the multicenter ID-IRI study. Eur J Clin Microbiol Infect Dis. 2017; 36(8): 1455-62. PubMed Abstract | Publisher Full Text

21. Ablett Jj: Tetanus and the anaesthetist; a review of the symptomatology and the recent advances in treatment. Br J Anaesth. 1956; 28(6): 258-73. PubMed Abstract | Publisher Full Text

22. Thwaites $L$, Duoc NVT, Trung TN: Long-term outcome in tetanus cohort: 04TS. University of Oxford, 2021.

http://ora.ox.ac.uk/objects/uuid:af44c622-a7b8-44b2-827e-056623dd49a8 


\section{Open Peer Review}

\section{Current Peer Review Status: ? ?}

\section{Version 1}

Reviewer Report 07 June 2021

https://doi.org/10.21956/wellcomeopenres.18452.r43840

(C) 2021 Hashmi M. This is an open access peer review report distributed under the terms of the Creative Commons Attribution License, which permits unrestricted use, distribution, and reproduction in any medium, provided the original work is properly cited.

\section{Madiha Hashmi}

Department of Critical Care Medicine, Ziauddin University, Karachi, Pakistan

Favorable outcomes of adult patients with generalized tetanus are attributed to consistent, holistic, evidence-based and protocolized management by a highly experienced team at a specialist infectious diseases hospital in Southern Vietnam that receives 250-350 adult patients annually.

This prospective observational study describes the pragmatic management and outcomes of 180 patients in two cohorts (August 2016 - March 2017 and January - July 2018) that were followed daily till hospital discharge. Factors like age, need for mechanical ventilation (50\%), autonomic nervous system dysfunction (25\%), hospital acquired infections (43\%) and median length of ICU stay (15 [8-23] days) is comparable to reports from other LMICs but outcome is significantly better ( $2.8 \%$ vs. $44 \%$ from a Brazilian ICU).

\section{Study Design:}

The prospective observational study design describes better outcomes of adult patients admitted with generalized tetanus based on a high volume of cases referred to this tertiary center and more than 10 years experience of the team rather than adherence to the elements of the management protocol. Randomization of patients to either receive a bundled care or usual care or studying outcomes based on adherence to the holistic protocol will improve the quality of evidence generated.

The full exclusion criteria are not mentioned. It is not clear why ALL patients admitted during the two study periods were not included in the study and 80 patients (out of 160) in the first study period and 20 (patients (out of 120) in the second study period were excluded.

\section{Reproducibility:}

To allow others to benefit from their holistic protocols more details of various elements of the protocol are needed like recommended timings of antitoxins, antibiotics, tracheostomy or mechanical ventilation, details of wound management, targets of nutrition therapy, infection prevention and control protocols, routine prophylactic therapies and rehabilitation 
protocols, etc.

Is the work clearly and accurately presented and does it cite the current literature? Yes

Is the study design appropriate and is the work technically sound?

Partly

Are sufficient details of methods and analysis provided to allow replication by others? Yes

If applicable, is the statistical analysis and its interpretation appropriate? Yes

Are all the source data underlying the results available to ensure full reproducibility? Partly

Are the conclusions drawn adequately supported by the results? Yes

Competing Interests: No competing interests were disclosed.

Reviewer Expertise: surgical intensive care, anesthesia, critical care epidemiology

I confirm that I have read this submission and believe that I have an appropriate level of expertise to confirm that it is of an acceptable scientific standard.

Reviewer Report 01 June 2021

https://doi.org/10.21956/wellcomeopenres.18452.r43839

(C) 2021 Vijayaraghavan B. This is an open access peer review report distributed under the terms of the Creative Commons Attribution License, which permits unrestricted use, distribution, and reproduction in any medium, provided the original work is properly cited.

\section{Bharath Kumar Tirupakuzhi Vijayaraghavan}

Department of Critical Care Medicine, Apollo Hospitals, Chennai, Tamil Nadu, India

Thanks to the authors for this important submission.

Dr Van Hao and colleagues describe their experience and the management of 180 adult patients with tetanus from a single-ICU from Southern Vietnam. As pointed out by the authors, tetanus remains a vaccine preventable, but neglected disease in several LMICs. Data on management strategies and outcomes from high-performing centers is not only critical for guiding other hospitals in the region and from other LMICs, but also in setting the research agenda. 
I have a few comments for the authors to consider:

\section{Major comments:}

1. Why is there a gap in the study periods? Is this due to the unavailability of data in the intervening period? Or is it just a reflection of the fact that the authors use data from two readily available prospective cohorts (where information was collected for other reasons)?

A related question is if outcomes varied between the periods as well in the intervening period ( I recognize that the overall mortality is low and is perhaps unlikely to be very different between periods).

2. The outcomes are impressive - is this due to early identification and referral? Could the authors comment on this- perhaps provide information on time from symptom onset to admission?

3. Do the authors have information on intermediate-long term outcomes (survival, QoL, etc.) for these patients?

4. The authors provide data on nosocomial infections- how do these rates compare to the nontetanus intensive care admissions? And how do the outcomes for nosocomial infections compare? Do they have information on the pathogen profile (for instance proportion of multidrug resistant organisms)?

5. In their treatment protocol, I presume several of the treatments listed are 'OR' options rather than 'AND'- for example equine or human antitoxin, diazepam or midazolam etc. Can they clarify this in the table so that it is obvious to the readers?

I know this is not listed in their protocol- but are any intrathecal therapies used?

6. The section on 'description of cases who died': I agree that numbers are small, but the authors could provide the information given in this section as a table comparing 'dead' vs 'survivors'- they don't have to perform any hypothesis testing.

7. Table 2 provides the worst Ablett score during admission- numbers provided in this table do not match with those described under the text (in 'Results').

8. In the Discussion section, the authors could briefly highlight what they see as the research priorities for tetanus given their experience (for example, need for data on long-term outcomes, more stringent evaluation of therapies through trials, need for a registry tracking outcomes, etc.)

\section{Minor comments:}

1. Under 'Results': Line 3: Why 160 patients? Shouldn't this be 180 ?

Line 6: why 100 patients included out of 120 - reasons for exclusion of 20 ?

2. Under 'participants and data collection': what is the justification of the additional exclusion criteria (lines 7,8$)$ ? Is it just a carryover of the exclusion criteria of the original cohort? 
3. Under 'Discussion': Para 3- the authors say their protocol is 'evidence-based' but then go on to also say that most elements don't have much evidence. I know what they mean- but they could reframe these sentences.

4. The authors note that for a period these patients were managed in a 'special tetanus ICU'are there outcomes from that period? and if yes how do they compare to the later period?

5. I note their protocol includes elements around nutrition, discharge criteria, etc. Do they also have a plan for physiotherapy or rehab (in the later phases of illness)- these patients require prolonged periods of sedation/paralysis - hence the question.

Is the work clearly and accurately presented and does it cite the current literature? Yes

Is the study design appropriate and is the work technically sound? Yes

Are sufficient details of methods and analysis provided to allow replication by others? Yes

If applicable, is the statistical analysis and its interpretation appropriate? Not applicable

Are all the source data underlying the results available to ensure full reproducibility? Yes

Are the conclusions drawn adequately supported by the results? Yes

Competing Interests: No competing interests were disclosed.

Reviewer Expertise: My clinical and research area of interest is broadly critical care - I also have specific experience in the management of critically ill patients with tetanus.

I confirm that I have read this submission and believe that I have an appropriate level of expertise to confirm that it is of an acceptable scientific standard, however I have significant reservations, as outlined above. 
Author Response 23 Jun 2021

C Louise Thwaites, Oxford University Clinical Research Unit, Ho Chi Minh City, Vietnam

Why is there a gap in the study periods? Is this due to the unavailability of data in the intervening period? Or is it just a reflection of the fact that the authors use data from two readily available prospective cohorts (where information was collected for other reasons)?

The latter is correct. This has been clarified in the text in the methods section.

A related question is if outcomes varied between the periods as well in the intervening period ( $I$ recognize that the overall mortality is low and is perhaps unlikely to be very different between periods).

We have included the overall death rate of $4 \%$ in ALL hospital admissions in the results section. This rate includes all the 3 years and all patients (not just those enrolled). As the first cohort excluded those who could not walk, and could potentially have excluded the most severe group of patients as discussed in the Discussion section.

The outcomes are impressive - is this due to early identification and referral? Could the authors comment on this- perhaps provide information on time from symptom onset to admission?

This has been added after the Tetanus Severity Score.

Do the authors have information on intermediate-long term outcomes (survival, QoL, etc.) for these patients?

Long-term outcomes are available in the first cohort of these patients and are published separately. This has been added and cited again.

The authors provide data on nosocomial infections- how do these rates compare to the nontetanus intensive care admissions? And how do the outcomes for nosocomial infections compare? Do they have information on the pathogen profile (for instance proportion of multidrug resistant organisms)?

For this study, we have not addressed this specifically. We have in previous studies examined and compared rates of nosocomial infections - as tetanus patients stay for long periods of time but have relatively little multi-organ failure compared to other patients with similar length of stay, analysis is fairly complex and has not been included here. (See PLoS One. 2018 Sep 7;13(9):e0203600)

In their treatment protocol, I presume several of the treatments listed are 'OR' options rather than 'AND'- for example equine or human antitoxin, diazepam or midazolam etc. Can they clarify this in the table so that it is obvious to the readers?

Thank you - these have been clarified.

I know this is not listed in their protocol- but are any intrathecal therapies used? 
No these are not currently used.

The section on 'description of cases who died': I agree that numbers are small, but the authors could provide the information given in this section as a table comparing 'dead' vs 'survivors'- they don't have to perform any hypothesis testing.

This has been done and a table added.

Table 2 provides the worst Ablett score during admission-numbers provided in this table do not match with those described under the text (in 'Results').

The initial results section contains the 28 patients with severe on admission, the table contains the number of patients with severe scores ( 3 or 4 ) during admission. The text has been altered to clarify this.

In the Discussion section, the authors could briefly highlight what they see as the research priorities for tetanus given their experience (for example, need for data on long-term outcomes, more stringent evaluation of therapies through trials, need for a registry tracking outcomes, etc.)

Minor comments:

Under 'Results': Line 3: Why 160 patients? Shouldn't this be 180?

This was not clear - 80/160 admissions during the first period were enrolled in this study and 100/120 admissions during the second period were enrolled. The text has been changed.

Line 6: why 100 patients included out of 120- reasons for exclusion of 20?

As above. Entry criteria are given in the methods.

Under 'participants and data collection': what is the justification of the additional exclusion criteria (lines 7,8)? Is it just a carryover of the exclusion criteria of the original cohort?

Yes - text has been altered.

Under 'Discussion': Para 3- the authors say their protocol is 'evidence-based' but then go on to also say that most elements don't have much evidence. I know what they mean-but they could reframe these sentences.

Thank you - we have removed these/ changed to 'best-available evidence'

The authors note that for a period these patients were managed in a 'special tetanus ICU'- are there outcomes from that period? and if yes how do they compare to the later period?

Yes, we have data - added in the discussion section and cited. 
I note their protocol includes elements around nutrition, discharge criteria, etc. Do they also have a plan for physiotherapy or rehab (in the later phases of illness)- these patients require prolonged periods of sedation/paralysis - hence the question.

Currently, these are not written in the protocol but we are aiming to develop these. This has been added to the discussion in the 'priorities' and future section.

Competing Interests: No competing interests were disclosed.

Reviewer Report 28 May 2021

https://doi.org/10.21956/wellcomeopenres.18452.r43838

(C) 2021 Bonell A. This is an open access peer review report distributed under the terms of the Creative Commons Attribution License, which permits unrestricted use, distribution, and reproduction in any medium, provided the original work is properly cited.

\section{Ana Bonell}

${ }^{1}$ MRC Unit The Gambia, London School of Hygiene and Tropical Medicine, Fajara, The Gambia

2 Centre on Climate Change and Planetary Health, London School of Hygiene and Tropical Medicine, London, UK

This study presents outcome data for patients with severe tetanus who were treated according to a set treatment protocol developed in an intensive care unit in Vietnam. Data was collected from 2016-2018 and includes 180 patients. Mortality outcomes for this cohort is very low (2.8\%) compared to other published studies from LMICs.

Thank you for the opportunity to review this study detailing your standardised protocol. I have a few minors points for your consideration:

Is it possible to make figure 1 into a flowchart? This would be easier for clinicians to follow. Or potentially a checklist like the surgical checklist for example so that clinicians can easily see if they have missed any points.

Results: In the results section, please check IQR of median age of patients that died and check median age - it doesn't look correct.

I would like to understand the hospital acquired infection rate in context - how does this compare to other conditions on that specific ICU and also compared to other tetanus cohorts (43\% is high).

In the discussion, please can you add the case fatality rates from other settings for direct comparison (e.g. https://pubmed.ncbi.nlm.nih.gov/33824951/) ${ }^{1}$

\section{References}


1. Olum S, Eyul J, Lukwiya DO, Scolding N: Tetanus in a rural low-income intensive care unit setting. Brain Commun. 2021; 3 (1): fcab013 PubMed Abstract | Publisher Full Text

Is the work clearly and accurately presented and does it cite the current literature? Yes

Is the study design appropriate and is the work technically sound?

Yes

Are sufficient details of methods and analysis provided to allow replication by others? Yes

If applicable, is the statistical analysis and its interpretation appropriate? Yes

Are all the source data underlying the results available to ensure full reproducibility? Yes

Are the conclusions drawn adequately supported by the results? Yes

Competing Interests: No competing interests were disclosed.

Reviewer Expertise: Anaesthetics and intensive care | climate change and maternal health I confirm that I have read this submission and believe that I have an appropriate level of expertise to confirm that it is of an acceptable scientific standard, however I have significant reservations, as outlined above.

Author Response 23 Jun 2021

C Louise Thwaites, Oxford University Clinical Research Unit, Ho Chi Minh City, Vietnam

Is it possible to make figure 1 into a flowchart? This would be easier for clinicians to follow. Or potentially a checklist like the surgical checklist for example so that clinicians can easily see if they have missed any points.

This is a very good suggestion. Currently, the purpose of this piece was to publish in English the protocol which is already in use in the Hospital for Tropical Diseases. However, the idea to create a flow-chart check list is excellent and we will work on defining the action/stopstart points.

Results: In the results section, please check IQR of median age of patients that died and check median age - it doesn't look correct.

This has been checked and now is included in Table 3 
I would like to understand the hospital acquired infection rate in context - how does this compare to other conditions on that specific ICU and also compared to other tetanus cohorts (43\% is high).

In this study, we have not specifically looked at that, however previous studies have examined this. We have included a discussion around this in the discussion section. Essentially what we have found in previous studies is that although rates are high, this is generally due to the length of ICU stay and that outcomes are actually relatively good.

In the discussion, please can you add the case fatality rates from other settings for direct comparison (e.g. https://pubmed.ncbi.nlm.nih.gov/33824951/)1.

These have been added and the citation above also included.

Competing Interests: No competing interests were disclosed. 